\title{
Severe colitis related to granulomatosis with polyangiitis (Wegener's granulomatosis)
}

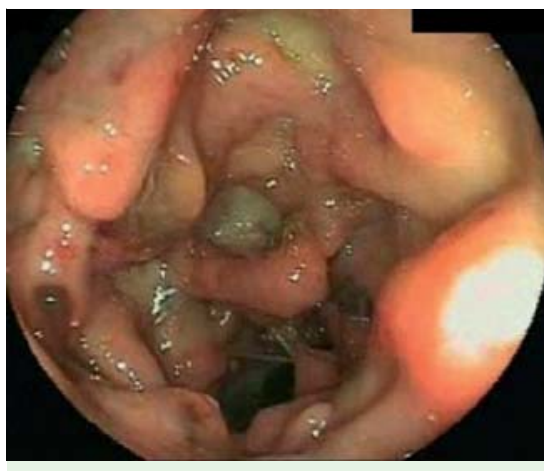

Fig. 1 Colonoscopy in a 58-year-old man with weakness, cough, weight loss, and intermittent painless rectal bleeding showing extensive deep ulcer craters covered with fibrinous exudates.

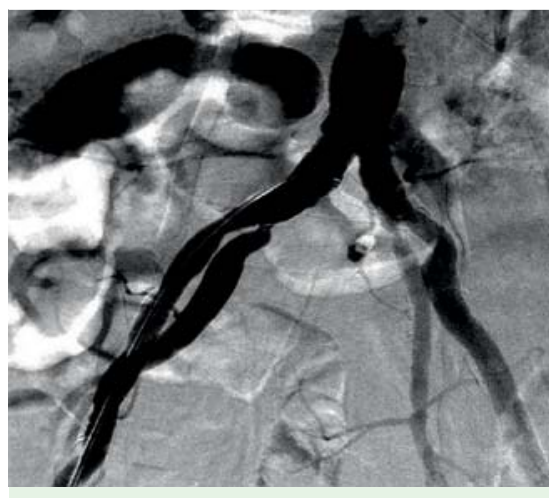

Fig.3 Angiography showing incomplete stenosis of the proximal portion of the left internal iliac artery.

A 58-year-old man presented with weakness, cough, weight loss, and intermittent painless rectal bleeding for 2 weeks. He was on no medication and gave no history of smoking or alcohol use. His family history was unremarkable. On examination, his abdomen was soft and diffusely tender. Blood tests showed the following results: white cell count $13 \times 10^{9} / \mathrm{L}$, hemoglobin $8.1 \mathrm{~g} / \mathrm{dL}$, alanine aminotransferase $31 \mathrm{U} / \mathrm{L}$, albumin $2.9 \mathrm{~g} / \mathrm{dL}$, creatinine $0.5 \mathrm{mg} / \mathrm{dL}$, erythrocyte sedimentation rate (ESR) $93 \mathrm{~mm} / \mathrm{h}, \quad$ CRP $160 \mathrm{mg} / \mathrm{L}$, complement C3 $0.63 \mathrm{~g} / \mathrm{L}$ (normal range $0.8-1.52 \mathrm{~g} / \mathrm{L}$ ) with no hypergammaglobulinemia. Proteinase 3 antineutrophil cytoplasmic antibody (ANCA) and myeloperoxidase ANCA were negative.

Colonoscopy showed extensive deep ulcer craters covered with fibrinous exudates ( Fig.1). Biopsies from an ulcer in the

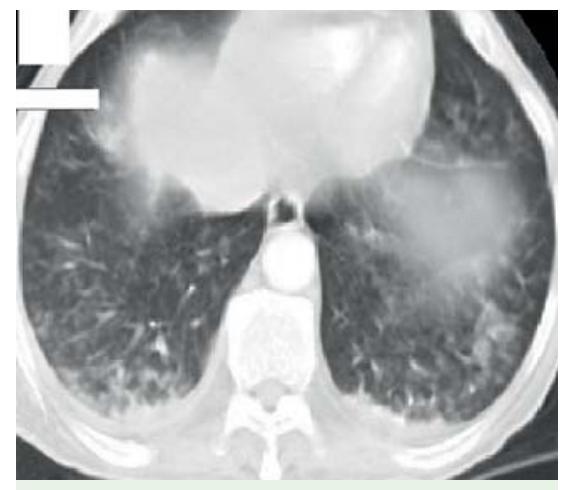

Fig.2 Thoracic computed tomography (CT) scan showing bilateral perihilar infiltration, and ground-glass opacities and areas of consolidation in the middle right and left lobe.

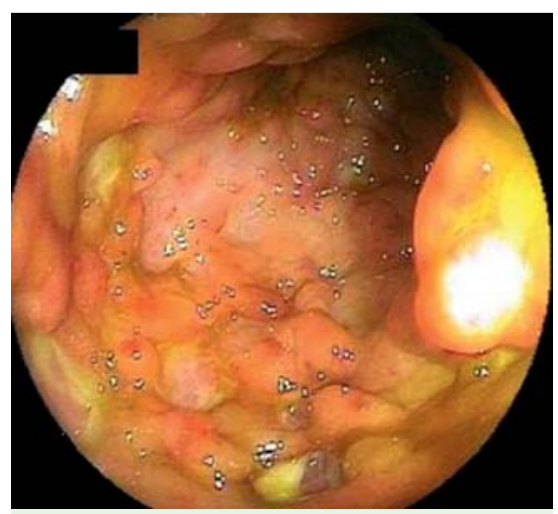

Fig. 4 Repeat colonoscopy after 8 weeks of intensive immunosuppressive therapy showing regression of the deep ulcers.

rectum were carefully performed. Thoracic computed tomography (CT) showed bilateral perihilar infiltration, and groundglass opacities and areas of consolidation in the middle right and left lobe ( Fig. 2). Because of the high suspicion of ischemia on colonoscopy, angiography was performed. This showed incomplete stenosis in the proximal portion of the left internal iliac artery ( $\bullet$ Fig.3). Biopsies from the ulcer showed nonspecific ulceration with no colonic crypts or granuloma formation. The patient was diagnosed as having granulomatosis with polyangiitis (GPA) presenting with severe colonic involvement. Intensive immunosuppression with high doses of corticosteroids and cyclophosphamide was started. Regression of the deep ulcers was found on repeat colonoscopy after 8 weeks of intensive immunosuppressive therapy ( $\mathbf{F i g} .4$ ).
GPA, also known as Wegener's granulomatosis, is an idiopathic ANCA-positive vasculitis involving vessels of small and medium size in many organs [1]. The respiratory tract, lungs, and kidneys are the organs most often affected; it very rarely involves organs of the gastrointestinal system. Gastrointestinal involvement has been described in $10 \%-24 \%$ of patients with GPA [2]. From the reports in the literature, cases respond well to intensive immunosuppressive treatment [3], but close follow-up is required to monitor for relapse and determine the involvement of other organs.

Endoscopy_UCTN_Code_CCL_1AD_2AF

Competing interests: None

\section{Fatih Karaahmet ${ }^{1}$, Serta Kılıncalp ${ }^{1}$, Yusuf Coskun ${ }^{1}$, Sahin Coban', Ilhami Yuksel ${ }^{1,2}$}

${ }^{1}$ Department of Gastroenterology, Dıskapı Yıldırım Beyazıt Educational and Research Hospital, Ankara, Turkey

2 Department of Gastroenterology, Yıldırım Beyazıt University School of Medicine, Ankara, Turkey

\section{References}

1 Lyons PA, Rayner TF, Trivedi S et al. Genetically distinct subsets within ANCA-associated vasculitis. N Engl J Med 2012; 367: 214-223

2 Izzedine $H$, Lacaille S, Deray G. An unusual presentation of relapsing Wegener's granulomatosis. Nephrol Dial Transplant 2001; 16: $1511-1512$

3 Kuwahara Y, Shima Y, Tanaka T et al. Successful treatment with intravenous cyclophosphamide pulse therapy of severe intestinal involvement in Wegener's granulomatosis. Scand J Rheumatol 2006; 35: 243 - 245

\section{Bibliography}

DoI http://dx.doi.org/

10.1055/s-0034-1365101

Endoscopy 2014; 46: E175

(c) Georg Thieme Verlag KG

Stuttgart · New York

ISSN 0013-726X

\section{Corresponding author}

\section{Fatih Karaahmet, MD}

Department of Gastroenterology

Dışkapı Yıldııım Beyazıt Educational and Research

Hospital

06080 Altındag-Ankara

Turkey

Fax: +90-312-3186690

fatih_ares@yahoo.com.tr 